\title{
Clinical and Histopathological Findings of Frontal Fibrosing Alopecia-Associated Lichen Planus Pigmentosus
}

\author{
Ricardo Romiti Camila Fátima Biancardi Gavioli Alessandra Anzai \\ Andréia Munck Carolina Oliveira Costa Fechine Neusa Y.S. Valente \\ Dermatological Outpatient Clinic, Hospital das Clínicas, Medical School of the University of São Paulo, \\ São Paulo, Brazil
}

\section{Keywords}

Alopecia · Frontal fibrosing alopecia - Cutaneous lichen planus · Histopathological findings - Lichen planus pigmentosus $\cdot$ Skin phototypes

\begin{abstract}
Background: Frontal fibrosing alopecia (FFA) is a primary lymphocytic scarring alopecia occurring mainly in postmenopausal women. A range of facial lesions have been described in FFA, such as lichen planus (LP) pigmentosus, red dots, facial papules, and perifollicular and diffuse erythema. These lesions can be the first sign of FFA. LP pigmentosus is a rare variant of LP. The first description of LP pigmentosus associated with FFA (in 2012) reported 22 cases of LP pigmentosus among 44 cases of FFA affecting South African patients. Methods: We reviewed 16 FFA patients with LP pigmentosus and the histopathological findings of the biopsy of LP pigmentosus in 9 patients. Results: Most patients had intermediate skin phototypes (III-IV; $n=10 ; 62 \%$ ). The age at onset of LP pigmentosus ranged from 30 to 60 years. The most common histopathological findings were epidermal atrophy, basal cell degeneration, interfollicular inflammatory infiltrate and melanophages, and perifollicular changes. Other findings not previously described in LP pigmentosus
\end{abstract}

\section{KARGER}

(๑) 2017 S. Karger AG, Basel

E-Mail karger@karger.com

www.karger.com/sad were inflammation and interface changes on sweat duct epithelia (acrosyringium and superior dermal duct), and lichenoid perisebaceitis. Conclusions: Histology of our cases confirmed previous findings and showed a high incidence of perifollicular involvement with occasional changes affecting sebaceous and sweat glands.

(c) 2017 S. Karger AG, Basel

\section{Introduction}

Frontal fibrosing alopecia (FFA) is a primary lymphocytic scarring alopecia occurring mainly in postmenopausal women, clinically characterized by progressive recession of the frontotemporal hairline $[1,2]$. Most reported cases involve Caucasians, but African-descendent patients and Hispanics have also been described [3,4].

Lichen planus (LP) pigmentosus is a rare variant of LP presenting clinically as a diffuse, reticulated, blotchy, linear or perifollicular slate gray to brownish-black pigmentation on sun-exposed areas, mainly the face and the neck [5-7].

The first description of LP pigmentosus associated with FFA reported 22 cases of LP pigmentosus among 44 cases of FFA affecting South African patients. In all cases, 
Table 1. Demographic and clinical data from the patients

\begin{tabular}{|c|c|c|c|c|c|c|c|c|}
\hline Patient & Gender & Phototype & $\begin{array}{l}\text { Onset of FFA, } \\
\text { years }\end{array}$ & $\begin{array}{l}\text { Pre- or post- } \\
\text { menopause? }\end{array}$ & $\begin{array}{l}\text { Onset of LP } \\
\text { pigmentosus, } \\
\text { years }\end{array}$ & $\begin{array}{l}\text { Interval between FFA } \\
\text { and LP pigmentosus, } \\
\text { years }\end{array}$ & $\begin{array}{l}\text { Hair loss at other } \\
\text { sites (and which } \\
\text { site) }\end{array}$ & $\begin{array}{l}\text { Facial } \\
\text { papules }\end{array}$ \\
\hline 2 & $\mathrm{~F}$ & IV & 50 & pre & 52 & post FFA & $\mathrm{N}$ & $\mathrm{N}$ \\
\hline 3 & M & IV & 34 & - & 32 & 2 & limbs & $\mathrm{Y}$ \\
\hline 4 & $\mathrm{~F}$ & IV & 56 & post & 56 & 0 & NA & $\mathrm{Y}$ \\
\hline 6 & $\mathrm{~F}$ & IV & 56 & post & 47 & 9 & limbs & $\mathrm{N}$ \\
\hline 7 & $\mathrm{~F}$ & IV & 54 & post & 40 & 14 & limbs & $\mathrm{N}$ \\
\hline 8 & $\mathrm{~F}$ & IV & 37 & pre & 34 & 3 & NA & $\mathrm{Y}$ \\
\hline 9 & $\mathrm{~F}$ & $\mathrm{~V}$ & 68 & post & 50 & 18 & $\mathrm{~N}$ & $\mathrm{~N}$ \\
\hline 10 & $\mathrm{~F}$ & IV & 59 & pre & 30 & 29 & limbs & $\mathrm{Y}$ \\
\hline 11 & $\mathrm{~F}$ & III & 56 & post & 60 & post FFA & $\mathrm{N}$ & $\mathrm{N}$ \\
\hline 16 & $\mathrm{~F}$ & II & 54 & pre & 54 & 0 & limbs & $\mathrm{Y}$ \\
\hline Total & $15 / 16 \mathrm{~F}$ & $\begin{array}{l}2 \mathrm{II}+10 \mathrm{III} / \\
\mathrm{IV}+4 \mathrm{~V} / \mathrm{VI}\end{array}$ & 52 & $5 / 15$ (pre) & $30-60(47)$ & $2-29(10)$ & $62 \%$ & $50 \%$ \\
\hline
\end{tabular}

FFA, frontal fibrosing alopecia; LP, lichen planus; N, no; Y, yes; NA, not available.

the cutaneous involvement preceded the alopecia by 6-36 months [5]. Since 2012, only 2 further reports of FFAassociated LP pigmentosus have been published in the English literature $[8,9]$.

\section{Material and Methods}

In order to detect the prevalence of this association in our FFA patients, we reviewed charts and pictures of all FFA patients currently seen at the Hair Clinic of the University of São Paulo, Brazil.

The review of 114 patients diagnosed with FFA (confirmed by histology) attending the University of São Paulo Hair Clinic revealed 16 patients (14\%) with the clinical diagnosis of LP pigmentosus on the face. Patients with other autoimmune diseases that present with interface dermatitis were excluded from the analysis. Clinical diagnosis of LP pigmentosus was corroborated by histology in 9 patients.

\section{Results}

Demographic and clinical data from the 16 patients with LP pigmentosus can be found in Table 1. Most patients had intermediate skin phototypes (III-IV; $n=10$; $62 \%)$. High skin phototypes (V-VI) were seen in $25 \%$ of patients, while only $2(12.5 \%)$ had phototype II. None of our patients had phototype I. There were 15 women (94\%) and 1 man (6\%). The age at onset of LP pigmentosus ranged from 30 to 60 years (mean 47). Most women were postmenopausal $(n=11 ; 73 \%)$. All patients had frontotemporal hair loss and eyebrow alopecia. Hair loss at other body sites was seen in $60 \%$, while facial papules were observed in $50 \%$ of them. Most of the patients $(7 / 16$; 43.7\%) referred LP pigmentosus onset well before scalp alopecia, with a mean lag time of 10 years. Two presented skin changes at the same time as hair loss and 5 presented with LP pigmentosus after scalp hair loss. In 2 patients, this information could not be elicited.

Histopathology analysis of 9 biopsies of LP pigmentosus showed epidermal atrophy and basal cell vacuolar change in most of the cases $(7 / 9 ; 78 \%)$ (Fig. 1). Epidermal basal membrane thickening was seen in 4 patients with PAS staining $(4 / 8 ; 50 \%)$. Interfollicular inflammatory infiltrates were present in 6/9 (66.6\%) and interfollicular melanophages were seen in all cases. Perifollicular changes were observed in all patients: melanophages were seen in $100 \%$ of cases, inflammatory infiltrates in $3 / 7$ (42.8\%), lichenoid infiltrates in 2, follicular basal cell vacuolar change in $4 / 7$ (57\%) and basal membrane thickening in
60

Skin Appendage Disord 2017;3:59-63 DOI: $10.1159 / 000456038$
Romiti et al. 
Fig. 1. Clinical presentation of LP pigmentosus (left). Atrophic epidermis with vacuolar degeneration of basal cells and melanophages in the upper dermis. $\times 400$ (right).
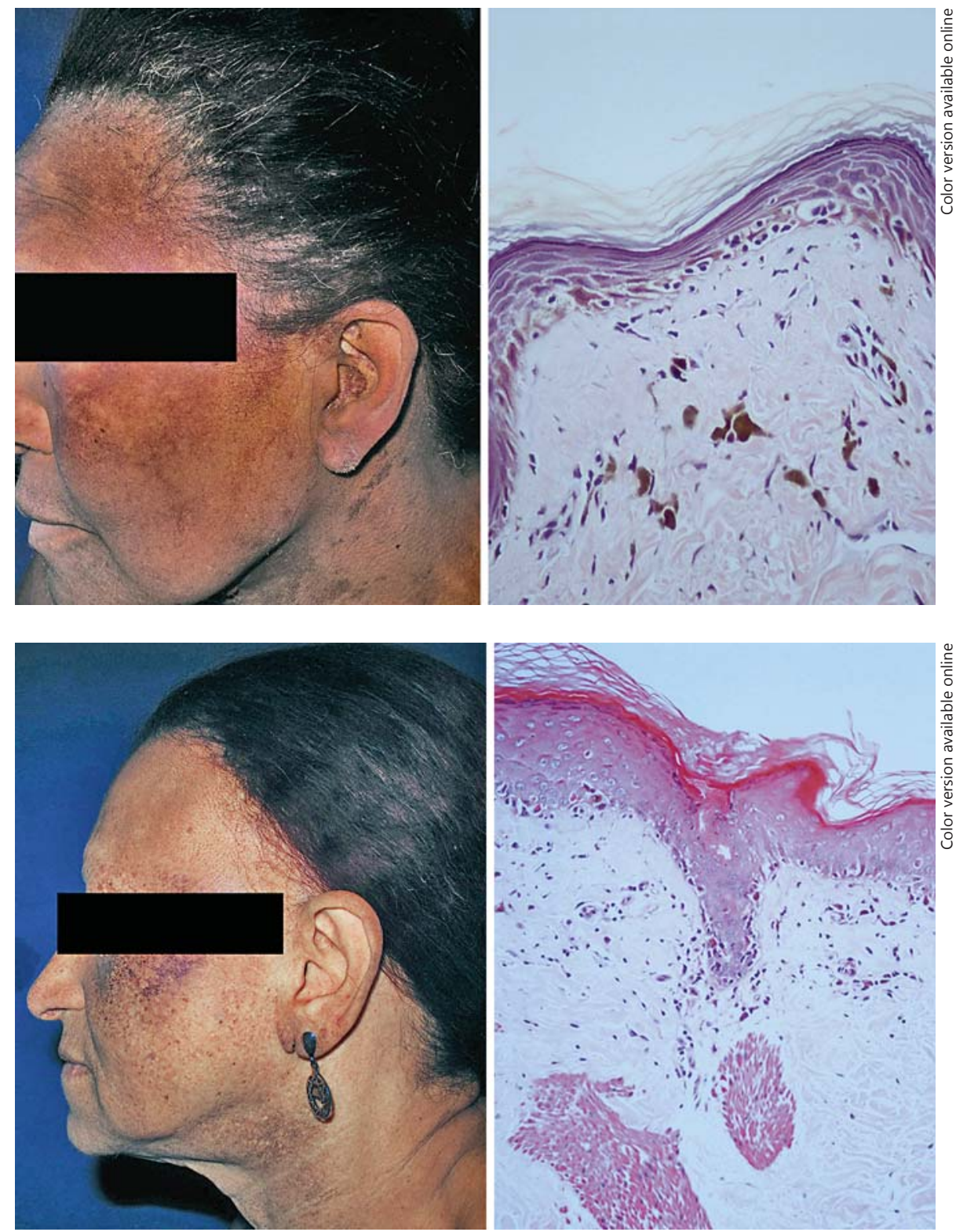

Fig. 2. Clinical presentation of LP pigmentosus (left). Vacuolar interface dermatitis in the acrosyringium and in the interadnexal epidermis. $\times 200$ (right). patients, and $\operatorname{IgA}$ and $\mathrm{C} 3$ at the dermoepidermal junction in 1 patient (Table 2). None of the biopsies showed mucin deposits nor follicular dilation with keratin plugs. Beyond that, all patients had negative antinuclear antibody and no clinical criteria for systemic lupus.

\section{Discussion}

Clinical and histopathological features of LP pigmentosus were first described in 1974 by Bhutani et al. [10] in Indian patients. Histopathological findings of LP pig- 
Table 2. Histopathological features of LP pigmentosus

\begin{tabular}{|c|c|c|c|c|c|c|c|c|c|c|c|c|c|}
\hline 1 & malar & + & + & - & NA & - & - & + & NA & NA & - & + & NA \\
\hline 2 & arm & + & + & + & - & + & - & + & + & + & + & + & + \\
\hline 3 & malar & - & - & - & + & NA & NA & $\mathrm{NA}$ & - & - & + & + & + \\
\hline 6 & face & + & - & - & - & ++ & + & + & - & + & - & + & + \\
\hline 7 & face & - & + & - & - & NA & NA & NA & - & - & + & + & + \\
\hline 8 & malar & + & + & - & + & - & - & - & - & - & + & + & + \\
\hline $\begin{array}{l}9 \\
\text { Total }\end{array}$ & chin & $\begin{array}{l}+ \\
(7 / 9)\end{array}$ & $\begin{array}{l}+ \\
(7 / 9)\end{array}$ & $\begin{array}{l}- \\
(1 / 9)\end{array}$ & $\begin{array}{l}+ \\
(4 / 8)\end{array}$ & $\begin{array}{l}- \\
(3 / 7)\end{array}$ & $\begin{array}{l}+ \\
(4 / 7)\end{array}$ & $\begin{array}{l}- \\
(5 / 7)\end{array}$ & $\begin{array}{l}+ \\
(2 / 8)\end{array}$ & $\begin{array}{l}- \\
(3 / 8)\end{array}$ & $\begin{array}{l}+ \\
(6 / 9)\end{array}$ & $\begin{array}{l}+ \\
(9 / 9)\end{array}$ & $\begin{array}{l}- \\
(7 / 8)\end{array}$ \\
\hline
\end{tabular}

LP, lichen planus; NA, not available; +, present; -, absent.

mentosus include varying degrees of hyperkeratosis, thinning and basal cell vacuolar change of the epidermis, perivascular and/or perifollicular infiltrate, melanophages and a band-like infiltrate in the upper dermis [6]. Direct immunofluorescence rarely shows deposits of IgM or $\mathrm{C} 3$ at the dermoepidermal junction [6].

FFA-associated LP pigmentosus was first described by Dlova [5] in 2013 in more than 50\% of 44 FFA patients, mostly African women. After this first report, only 2 publications reported 1 Indian and 2 Hispanic women. Interestingly, a large FFA series published in 2014 reporting 355 patients with FFA did not mention LP pigmentosus in association with their findings. This fact may be due to racial characteristics of the studied population that consisted mainly of Caucasian patients, with only 3 black and 2 gypsy individuals. In our group, we found $14 \%$ of FFA patients with LP pigmentosus lesions, less frequently than the $55 \%$ of Dlova's series. This may be due to the lower skin phototypes studied among our Brazilian patients, and consequently the lower predisposition to LP pigmentosus.

Age at onset of LP pigmentosus in our patients was similar to previously published data, but our patients referred a much later onset of scalp involvement, and a more advanced disease. Dlova [5] found that in half of her cases, LP pigmentosus began many years before FFA, confirming that LP pigmentosus may precede scalp hair loss in some patients. Besides, she also suggests that early onset of FFA in her group might be related to tractioninduced alopecia, and this might explain the earlier onset of scalp hair loss in her patients compared to the rest of the world. All of our patients presented frontotemporal and eyebrow alopecia, with $60 \%$ also referring hair loss at other body sites and $50 \%$ presenting facial papules. The higher frequency of other clinical findings in our patients might indicate the more advanced stage of the disease at diagnosis.

Facial lesions in FFA were first described by Abbas et al. [11] in 2007, when he showed facial papules due to the involvement of vellus hair [12]. Later, in 2013, Dlova [5] reported her cases of facial LP pigmentosus associated with FFA; in 2014, Pirmez et al. [13] described follicular red dots in the glabellar and forehead areas, and, in 2015, López-Pestaña et al. [12] reported perifollicular and diffuse erythema and the gradual appearance of pigmented macules on facial skin, whose biopsies showed perifollicular and interfollicular lichenoid infiltrate. The description of facial lesions in FFA shows us that FFA is not restricted to the scalp and that facial involvement can be the first sign of FFA, which allows us to make an early diagnosis of FFA.

Histopathological and direct immunofluorescence findings in our series are similar to the results of LP pigmentosus previously published, concerning the epidermal and interfollicular changes. Perifollicular findings have only been mentioned before in 6 patients with a clinically follicular pattern. Our study detected frequent follicular involvement, with all cases presenting perifolllicular melanophages and $57 \%$ presenting interface changes on follicular epithelia and perifollicular inflammatory infiltrate. Of notice, we detected inflammatory changes in sweat gland duct of 2/7 and sebaceous gland inflamma- 
tory involvement in $1 / 7$. Sweat gland duct involvement was first seen in cutaneous lichen planus in 1987 by Enhamre and Lagerholm [14], but there are no reports about sweat gland involvement in LP pigmentosus. In conclusion, histology of our cases confirmed previous findings and showed a high incidence of perifollicular involvement with occasional changes affecting sebaceous and sweat glands.

\section{Statement of Ethics}

The patients of this article agree to have their photo published.

\section{Disclosure Statement}

There is no conflict of interest.

\section{References}

1 Lacarrubba F, Micali G, Tosti A: Absence of vellus hair in the hairline: a videodermatoscopic feature of frontal fibrosing alopecia. $\mathrm{Br}$ J Dermatol 2013;169:473-474.

2 Rácz E, Gho C, Moorman PW, Noordhoek Hegt V, Neumann HA: Treatment of frontal fibrosing alopecia and lichen planopilaris: a systematic review. J Eur Acad Dermatol Venereol 2013;27:1461-1470.

3 Miteva M, Whiting D, Harries M, Bernardes A, Tosti A: Frontal fibrosing alopecia in black patients. Br J Dermatol 2012;167:208-210.

4 Camacho Martínez F, García-Hernández MJ, Mazuecos Blanca J: Postmenopausal frontal fibrosing alopecia. Br J Dermatol 1999;140: 1181-1182.

5 Dlova NC: Frontal fibrosing alopecia and lichen planus pigmentosus: is there a link? $\mathrm{Br} \mathrm{J}$ Dermatol 2013;168:439-442.
6 Kanwar AJ, Dogra S, Handa S, Parsad D, Radotra BD: A study of 124 Indian patients with lichen planus pigmentosus. Clin Exp Dermatol 2003;28:481-485.

7 Al-Mutairi N, El-Khalawany M: Clinicopathological characteristics of lichen planus pigmentosus and its response to tacrolimus ointment: an open label, non-randomized, prospective study. J Eur Acad Dermatol Venereol 2010;24:535-540.

8 Rao R, Sarda A, Khanna R, Balachandran C: Coexistence of frontal fibrosing alopecia with lichen planus pigmentosus. Int J Dermatol 2014;53:622-624

9 Berliner JG, McCalmont TH, Price VH, Berger TG: Frontal fibrosing alopecia and lichen planus pigmentosus. J Am Acad Dermatol 2014;71:e26-e27.

10 Bhutani LK, Bedi TR, Pandhi RK, Nayak NC: Lichen planus pigmentosus. Dermatologica 1974;149:43-50.
11 Abbas O, Chedraoui A, Ghosn S: Frontal fibrosing alopecia presenting with components of Piccardi-Lassueur-Graham-Little syndrome. J Am Acad Dermatol 2007;57(2 Suppl):S15-S18.

12 López-Pestaña A, Tuneu A, Lobo C, Ormaechea N, Zubizarreta J, Vildosola S, et al: Facial lesions in frontal fibrosing alopecia (FFA): clinicopathological features in a series of 12 cases. J Am Acad Dermatol 2015;73:987.e1e6.

13 Pirmez R, Donati A, Valente NS, Sodré CT, Tosti A: Glabellar red dots in frontal fibrosing alopecia: a further clinical sign of vellus follicle involvement. Br J Dermatol 2014;170: 745-746.

14 Enhamre A, Lagerholm B: Acrosyringeal lichen planus. Acta Derm Venereol 1987;67: 346-350. 